\title{
Narrowband-to-Narrowband Frequency Reconfiguration with Harmonic Suppression Using Fractal Dipole Antenna
}

\author{
S. A. Hamzah, M. Esa, N. N. N. A. Malik, and M. K. H. Ismail \\ Department of Communication Engineering, UTM-MIMOS COE for Telecommunication Technology, Faculty of Electrical Engineering, \\ Universiti Teknologi Malaysia, 81310 UTM Johor Bahru, Johor, Malaysia
}

Correspondence should be addressed to S. A. Hamzah; sahamzah@gmail.com

Received 4 January 2013; Revised 26 June 2013; Accepted 2 July 2013

Academic Editor: Tayeb A. Denidni

Copyright (C) 2013 S. A. Hamzah et al. This is an open access article distributed under the Creative Commons Attribution License, which permits unrestricted use, distribution, and reproduction in any medium, provided the original work is properly cited.

Harmonic suppressed fractal antenna with switches named TMFDB25 is developed to select desired frequency band from $400 \mathrm{MHz}$ to $3.5 \mathrm{GHz}$. The radiating element length is changed to tune the operating frequency while the stub is used to eliminate the undesired harmonic frequency. The balun circuit is reduced by $75 \%$ from the original size. The antenna is built on a low loss material. It has the ability to select a single frequency out of fifteen different bands and maintain the omnidirectional radiation pattern properties. Furthermore, the antenna is designed, built, and tested. Simulation and measurement results show that the antenna operates well at the specific frequency range. Therefore, the antenna is suitable to be used for switching frequencies in the band of TV, GSM900/1800, 3G, ISM 2.4 GHz, and above.

\section{Introduction}

Narrowband-to-narrowband frequency reconfiguration with harmonic suppression is currently preferred to support communication system, particularly wireless application, due to single type of this antenna that can reduce the size of the RF front-end electronic circuits. However, this type of antenna operates at one specific frequency at one time. Besides, the implementation of switch can cause additional loss and thus reduce antenna efficiency. It is noteworthy that high bandwidth tunable reconfigurable antenna has several advantages if used compared to the initial antenna geometry. In contrast, the existence of high frequency mode may interfere the system operation and will require filter circuit at the output. This in turn will raise the complexity of the terminal circuit and the overall size of system. This problem can be overcome by using the state of art of tunable reconfigurable antenna which is able to suppress harmonic frequencies. In addition, its compact size has attracted many antenna designers in recent years.

Recently, combining narrowband configuration to tunable narrowband in order to eliminate harmonic frequencies is a new approach. The combination of tunable frequency, harmonic suppression, and size reduction technique is very important and a key to construct the most optimum reconfigurable antenna. The use of fractal antenna can decrease the physical size of the antenna.

As far as harmonic suppressed antenna (HSA) with switch is concerned, the harmonic suppressed reconfigurable antennas have been published previously in the literature $[1,2]$. The work on this type of antenna has been reported by using a linear dipole and log periodic dipole arrays, respectively. The first idea to create such antenna is presented in [1]. In a reconfigurable linear dipole in [1], 24 switches were used to control the antenna and the stub length. The antenna can change the operating frequency from a narrowbandto-narrowband features as well as suppress the harmonic frequency in the frequency range from $900 \mathrm{MHz}$ to $3.5 \mathrm{GHz}$. However, this antenna is large due to the antenna itself as well as the tapered balun used. The latter has 28 switches [2]. The antenna can configure the operating frequency, that is, from wideband to narrowband, by switching $\mathrm{ON}$ and $\mathrm{OFF}$ the radiating elements. Ideal switches are also used to control each pair of dipole arm and to switch the related stub. In addition, the antenna can operate from 1 to $3 \mathrm{GHz}$ and can be changed to other narrowband frequencies with large size.

Three antennas, namely, reconfigurable planar inverted-F antenna (RPIFA), reconfigurable ring patch antenna (RRPA), 
TABLE 1: Reconfigurable printed antenna with ideal switches.

\begin{tabular}{|c|c|c|c|c|c|c|}
\hline Reference & Antenna figure & $\begin{array}{l}\text { Antenna } \\
\text { structure }\end{array}$ & Switching band & $\begin{array}{c}\text { Frequency switching } \\
\text { technique }\end{array}$ & Switch types & $\begin{array}{c}\begin{array}{c}\text { Number of } \\
\text { switches }\end{array} \\
\end{array}$ \\
\hline [1] & $\begin{array}{c}\text { Mirkamali et al. } \\
\text { (2006) (University } \\
\text { of Birmingham, } \\
\text { UK) }\end{array}$ & Linear dipole & $\begin{array}{c}0.9 \mathrm{GHz}, 1.05 \mathrm{GHz} \\
1.205 \mathrm{GHz}, 1.460 \mathrm{GHz}, \\
1.750 \mathrm{GHz}, 2.05 \mathrm{GHz} \\
\text { and } 2.770 \mathrm{GHz}\end{array}$ & $\begin{array}{l}\text { Control effective } \\
\text { radiating length }\end{array}$ & $\begin{array}{l}\text { Metal patch } \\
\text { (ideal switch) }\end{array}$ & 24 \\
\hline$[2]$ & $\begin{array}{l}\text { Mirkamali et al. } \\
\text { (2010) (University } \\
\text { of Birmingham, } \\
\text { UK) }\end{array}$ & $\begin{array}{l}\text { Log periodic } \\
\text { dipole }\end{array}$ & $\begin{array}{l}\text { Mode 1: } 1-3 \mathrm{GHz} \\
\text { Mode 2: } 0.94 \mathrm{GHz} \text {, } \\
\text { Mode } 3: 1.217 \mathrm{GHz} \\
\text { Mode } 4: 1.477 \mathrm{GHz}\end{array}$ & $\begin{array}{l}\text { Control effective } \\
\text { radiating element }\end{array}$ & $\begin{array}{l}\text { Metal patch } \\
\text { (ideal switch) }\end{array}$ & 28 \\
\hline \multirow{3}{*}{ [3] } & \multirow{3}{*}{$\begin{array}{l}\text { Chamming (2003) } \\
\text { (Virginia } \\
\text { Polytechnic } \\
\text { Institute \& State } \\
\text { University) }\end{array}$} & PIFA & $\begin{array}{c}1.48 \mathrm{GHz}, 1.49 \mathrm{GHz}, \\
1.5 \mathrm{GHz}, 1.51 \mathrm{GHz} \text {, } \\
1.53 \mathrm{GHz} \text {, and } 1.51 \mathrm{GHz} \text {, } \\
\text { and } 1.54 \mathrm{GHz}\end{array}$ & $\begin{array}{l}\text { Change the ground } \\
\text { plane length }\end{array}$ & $\begin{array}{l}\text { Metal patch } \\
\text { (ideal switch) }\end{array}$ & 12 \\
\hline & & RRPA & $\begin{array}{c}1.50 \mathrm{GHz}, 1.52 \mathrm{GHz} \text {, and } \\
1.53 \mathrm{GHz}\end{array}$ & $\begin{array}{l}\text { Control the ring } \\
\text { width }\end{array}$ & $\begin{array}{l}\text { Metal patch } \\
\text { (ideal switch) }\end{array}$ & 80 \\
\hline & & RPFDA & $\begin{array}{c}0.94 \mathrm{GHz}, 1.01 \mathrm{GHz}, \\
1.03 \mathrm{GHz}, 1.04 \mathrm{GHz}, \\
1.05 \mathrm{GHz} \text {, and } 1.12 \mathrm{GHz}\end{array}$ & $\begin{array}{l}\text { Control the parasitic } \\
\text { element length }\end{array}$ & $\begin{array}{l}\text { Metal patch } \\
\text { (ideal switch) }\end{array}$ & 8 \\
\hline $\begin{array}{l}\text { Proposed in } \\
\text { this article }\end{array}$ & $\begin{array}{l}\text { Hamzah et al. } \\
\text { (2013) (Universiti } \\
\text { Teknologi } \\
\text { Malaysia, } \\
\text { Malaysia) }\end{array}$ & Koch dipole & $\begin{array}{c}691 \mathrm{MHz}, 725 \mathrm{MHz}, \\
734 \mathrm{MHz}, 865 \mathrm{MHz}, \\
953 \mathrm{MHz}, 987 \mathrm{MHz}, \\
1099 \mathrm{MHz}, 1160 \mathrm{MHz}, \\
1190 \mathrm{MHz}, 1270 \mathrm{MHz} \\
1440 \mathrm{MHz}, 1650 \mathrm{MHz}, \\
1880 \mathrm{MHz}, 2350 \mathrm{MHz} \\
\text { and } 3010 \mathrm{MHz}\end{array}$ & $\begin{array}{l}\text { Control effective } \\
\text { radiating length }\end{array}$ & $\begin{array}{l}\text { Metal patch } \\
\text { (ideal switch) }\end{array}$ & 50 \\
\hline
\end{tabular}

and reconfigurable folded parasitic dipole antenna (RPFDA) with switches have been proposed [3]. These antennas are integrated with 12,80 , and 8 switches, respectively. Through these published papers, the usage of ideal switches to demonstrate reconfigurable antennas is relevant. The features of antennas, that is, switching band, are tabulated and summarized in Table 1.

Reconfigurable antennas based on fractal shape have attracted many researchers in recent years. The antenna has many advantages such as large bandwidth, multifrequency and can reduce the antenna size. Koch and Hilbert curve as well as a Sierpinski Carpet are among the selected geometries to be studied for the antenna innovation. Many researchers have used these geometries in order to generate reconfigurable antenna that can configure the frequency or radiation pattern while exhibiting size reduction.

References [4-11] reported on reconfigurable fractal antennas. A Hilbert curve patch antenna uses six MEMS switches to configure the radiation pattern from $12.4 \mathrm{GHz}$ to $12.65 \mathrm{GHz}$ [4]. Four MEMS switches have been used in a Sierpinski gasket dipole to switch the frequency operation from $14 \mathrm{GHz}$ (band 1) to $8 \mathrm{GHz}$ and $25 \mathrm{GHz}$ (band 2) [6]. Other studies on reconfigurable fractal antennas use Sierpinski gasket, Hilbert curve, and von Koch geometry [5, 7-11]. Three switches located at the radiating element are used to change the operating frequency at $620 \mathrm{MHz}, 630 \mathrm{MHz}$, and $640 \mathrm{MHz}$ [7]. Five states of operating frequencies in Sierpinski gasket's antenna are demonstrated by controlling the switches condition [8]. Twelve switches have been used to tune $60 \mathrm{GHz}$ and $80 \mathrm{GHz}$ in the Koch patch antenna [9]. Thirty switches have been used in three-dimensional fractal tree antennas to configure operating frequency from $770 \mathrm{MHz}$ to $1570 \mathrm{MHz}$ [10]. Six switches have been employed in Sierpinski gasket antenna to tune the frequency at $2.4 \mathrm{GHz}$, $5.7 \mathrm{GHz}, 9.4 \mathrm{GHz}$, and $18 \mathrm{GHz}$ [11]. Four switches are used to configure the radiation pattern at $8.4 \mathrm{GHz}$ in a square patch fractal [5]. Some of them are summarized in Table 2.

Other published works on reconfigurable antenna are available in [12-17] which employed dipole antenna that is integrated with loop and open wire [12], U-Koch slotted monopole antenna [14], bow-tie antenna [15], UWB patch monopole antenna with spiral section [16], cedar-shaped fractal monopole antenna [17], and slotted monopole antenna (combination of square-ring and L-shaped linear) [13], respectively.

The work explained in this paper includes the research idea based on "harmonic suppressed frequency reconfigurable antenna" that can be obtained by controlling the radiation element length combined with internal filter. It is named as TMFDB25 antenna [18]. The balun circuit is reduced by $75 \%$ of height that made the antenna more practical. Moreover, the current is flowing directly through the terminal to the antenna input. The direction of current flow or current stop from the input terminal can be determined by means of open circuit stub placed at the terminal. An extensive simulation work has been carried out using two commercial software. The measurements are done using semianechoic chamber to validate the technique. The design consideration 
TABLE 2: Reconfigurable fractal antenna.

\begin{tabular}{|c|c|c|c|}
\hline Reference & Antenna structure & Number/type of switches & Comments \\
\hline [10] & Sierpinski gasket & 6/MEMS switch & $\begin{array}{c}\text { Changing the frequency from } 2.4 \mathrm{GHz}, \\
5.7 \mathrm{GHz} \text {, and } 9.4 \mathrm{GHz} \text { to } 18 \mathrm{GHz}\end{array}$ \\
\hline [6] & Sierpinski gasket & 4/MEMS switch & $\begin{array}{l}\text { Changing the frequency from } 7 \mathrm{GHz} \text {, and } \\
8 \mathrm{GHz}, 14 \mathrm{GHz} \text { to } 23 \mathrm{GHz}\end{array}$ \\
\hline [9] & Fractal tree & 204/copper strip (ideal switch) & $\begin{array}{l}\text { Changing the frequency from } 600 \mathrm{MHz} \text { to } \\
1600 \mathrm{MHz} \text { (approximately } 20 \text { bands) }\end{array}$ \\
\hline [7] & Hilbert curve & 2/metal patch (ideal switch) & $\begin{array}{l}\text { Changing the frequency from } 620 \mathrm{GHz} \text {, } \\
627 \mathrm{GHz} \text { to } 635 \mathrm{GHz}\end{array}$ \\
\hline$[4]$ & Hilbert curve & 8/metal patch (ideal switch) & Changing the pattern at $f=9.0 \mathrm{GHz}$ \\
\hline$[8]$ & Koch Patch & 18/copper strip (ideal switch) & Changing the pattern at $60 \mathrm{GHz}$ and $80 \mathrm{GHz}$ \\
\hline [11] & Square fractal loop & 4/metal patch (ideal switch) & Changing the pattern at $f=8.4 \mathrm{GHz}$ \\
\hline $\begin{array}{l}\text { Proposed } \\
\text { in this } \\
\text { paper }\end{array}$ & TMFDB25 & 50/copper strip (ideal switch) & $\begin{array}{l}\text { Changing the frequency from } 600 \mathrm{MHz} \text { to } \\
\text { 3.5 GHz with suppressed higher order mode }\end{array}$ \\
\hline
\end{tabular}

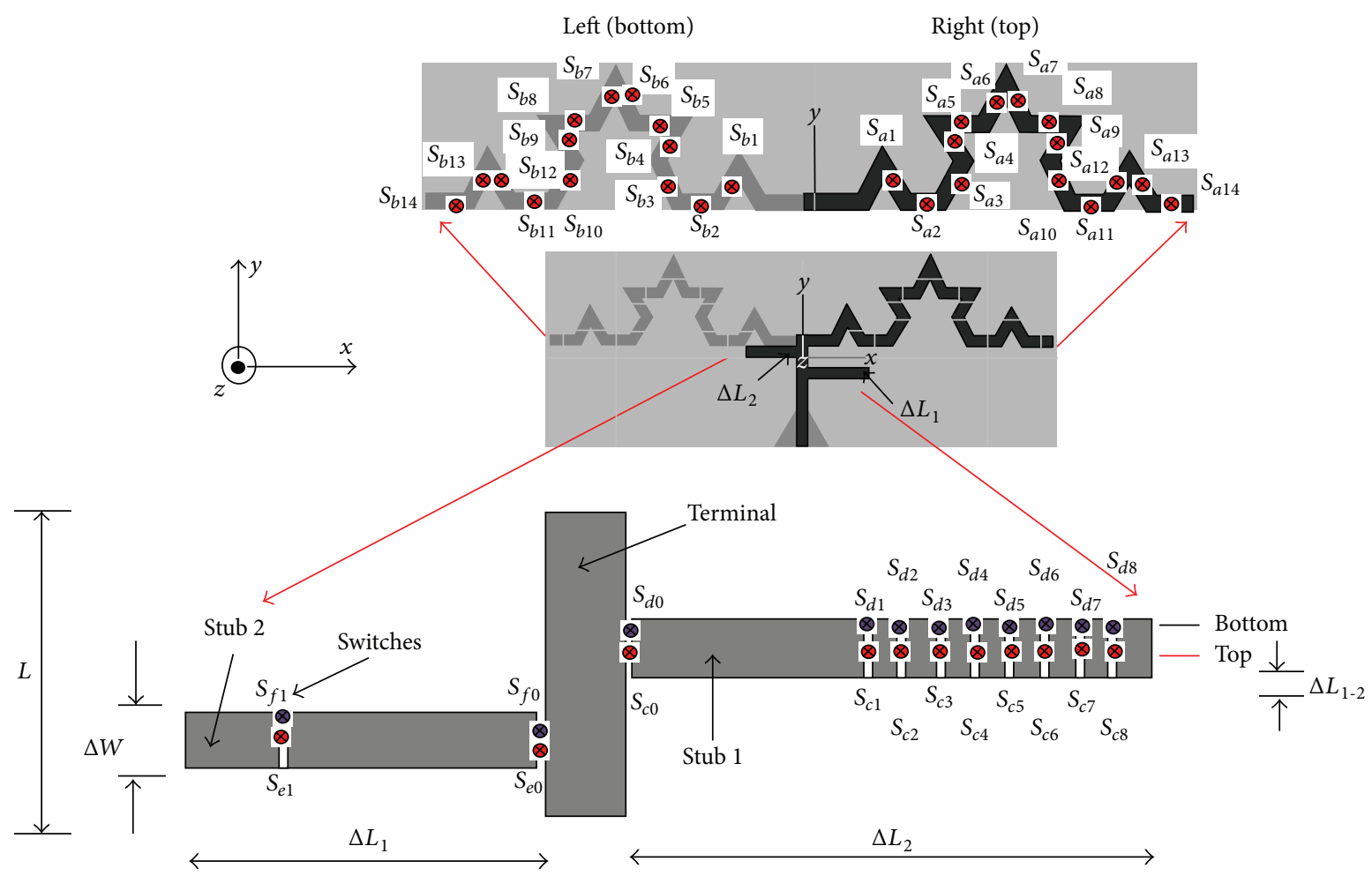

Figure 1: TMFDB25 antenna geometry.

is explained in Section 2 while all results are reported in Section 3. Finally, Section 4 concludes this paper.

\section{TMFDB25 Antenna}

The geometry of TMFDB25 is shown in Figure 1. The antenna is excited using microstrip line with small tapered balun $(75 \%$ size reduction) by an SMA connector. The antenna consists of a radiating element, stubs and terminal, tapered balun, and switches. Furthermore, the Koch curve is used to minimize the antenna size, while the double-sided structure is selected due to the ability to lock in the harmonic frequency. Figure 1 shows the geometrical layout of the antenna with a gap (slot) which acts as a switch. The slot size of $1.0 \mathrm{~mm} \times 1.5 \mathrm{~mm}$ is used to change the radiating element length as well as the stubs. For achieving reconfigurable capability, the antennas need to be able to change its length to resonate at the desired frequencies. In this design the elimination of higher order mode is considered and controlled via the implementation of open circuit stubs as presented in the figure. The antenna dipole arm is connected with 28 switches while 22 switches are used at the stubs to realize the reconfigurable antenna with harmonic suppression capability. 
TABLE 3: Switch configuration states for different length of radiating element. Units are in mm.

\begin{tabular}{|c|c|c|c|c|}
\hline Length ( $x$-axis) & Switch conditions (left arm) & Switch conditions (right arm) & MFDB25 Stub 1, Stub 2 & Band \\
\hline 137 & Sal to $\mathrm{Sal} 4$ are $\mathrm{ON}$ & Sb1 to $\mathrm{Sb} 14$ are $\mathrm{ON}$ & $(37,24)$ & Band 1 \\
\hline 128 & $\mathrm{Sa} 2$ to $\mathrm{Sa} 14$ are $\mathrm{ON}$ & $\mathrm{S} 2 \mathrm{~b}$ to $\mathrm{Sb} 14$ are $\mathrm{ON}$ & $(36,23)$ & Band 2 \\
\hline 120 & Sa3 to Sa14 are ON & S3b to Sb14 are ON & $(34,0)$ & Band 3 \\
\hline 112 & $\mathrm{Sa} 4$ to $\mathrm{Sa} 14$ are $\mathrm{ON}$ & $\mathrm{Sb} 4$ to $\mathrm{Sb} 14$ are $\mathrm{ON}$ & $(32,0)$ & Band 4 \\
\hline 104 & Sa5 to $\mathrm{Sa} 14$ are $\mathrm{ON}$ & Sb5 to $\mathrm{Sb} 14$ are $\mathrm{ON}$ & $(30,0)$ & Band 5 \\
\hline 96 & Sa6 to Sa14 are ON & Sb6 to Sb14 are ON & $(27,0)$ & Band 6 \\
\hline 88 & Sa7 to Sa14 are ON & $\mathrm{Sb} 7$ to $\mathrm{Sb} 14$ are ON & $(25,0)$ & Band 7 \\
\hline 84 & Sa8 to Sal4 are ON & $\mathrm{Sb} 8$ to $\mathrm{Sb} 14$ are $\mathrm{ON}$ & $(23,0)$ & Band 8 \\
\hline 76 & Sa9 to Sal4 are ON & Sb9 to Sb14 are ON & $(22,0)$ & Band 9 \\
\hline 66 & Sa10 to Sal4 are ON & Sb10 to Sb14 are ON & Not used & Band 10 \\
\hline 60 & Sall to Sal4 are ON & Sb11 to $\mathrm{Sb} 14$ are ON & Not used & Band 11 \\
\hline 52 & Sal2 to Sal4 are ON & Sb12 to Sb14 are ON & Not used & Band 12 \\
\hline 44 & Sal3 to Sal4 are ON & Sb13 to Sb14 are ON & Not used & Band 13 \\
\hline 36 & Sal4 is ON & $\mathrm{Sb} 14$ is $\mathrm{ON}$ & Not used & Band 14 \\
\hline 28 & All switches are OFF & All switches are OFF & Not used & Band 15 \\
\hline
\end{tabular}

TABLE 4: Effect of terminal length, $L$, on resonance in Figure 1.

\begin{tabular}{|c|c|c|c|c|c|c|c|}
\hline Resonance & $\begin{array}{c}L_{1}, \mathrm{~mm} \\
10\end{array}$ & $\begin{array}{c}L_{2}, \mathrm{~mm} \\
12\end{array}$ & $\begin{array}{c}L_{3}, \mathrm{~mm} \\
14\end{array}$ & $\begin{array}{c}L_{4}, \mathrm{~mm} \\
16\end{array}$ & $\begin{array}{c}L_{5}, \mathrm{~mm} \\
18\end{array}$ & $\begin{array}{c}L_{6}, \mathrm{~mm} \\
20\end{array}$ & $\begin{array}{c}L_{7}, \mathrm{~mm} \\
22\end{array}$ \\
\hline$f(\mathrm{GHz}), \mathrm{dB}$ & $0.74,-23$ & $0.74,-24$ & $0.74,-25$ & $0.74,-26$ & $0.74,-27$ & $0.74,-28$ & $0.74,-29$ \\
\hline 1st $\mathrm{HM}(\mathrm{GHz}), \mathrm{dB}$ & $2.02,-1.6$ & $1.98,-3$ & $1.98,-3$ & $1.99,-3$ & $1.99,-3$ & $1.99,-3$ & $1.99,-3$ \\
\hline 2nd HM (GHz), dB & $2.79,-1.8$ & $2.27,-4$ & $2.28,-4$ & $2.28,-4$ & $2.28,-3$ & $2.28,-3$ & $2.28,-3$ \\
\hline
\end{tabular}

TABLE 5: Effect of stubfilter's length on resonance in Figure 1 is location of stub 2 with respect to stub 1.

\begin{tabular}{|c|c|c|c|c|c|c|c|}
\hline \multirow{2}{*}{ Resonance } & \multicolumn{7}{|c|}{$\Delta L_{1-2}, \mathrm{~mm}$} \\
\hline & 0 & 1 & 2 & 3 & 4 & 5 & 6 \\
\hline$f(\mathrm{GHz}), \mathrm{dB}$ & $0.74,-22$ & $0.74,-29$ & $0.74,-23$ & $0.74,-23$ & $0.74,-27$ & $0.74,-24$ & $0.74,-23$ \\
\hline 1st HM (GHz), dB & $2.36,-31$ & $2,-2$ & $1.99,-3$ & $1.98,-3$ & $1.98,-5$ & $1.96,-7$ & $1.94,-12$ \\
\hline 2nd HM (GHz), dB & NA & $2.36,-13$ & $2.29,-6$ & $2.25,-2$ & NA & NA & NA \\
\hline
\end{tabular}

In this design conceptual, the frequency reconfiguration totally depends on the radiating element length while stubs 1, 2 suppressed their corresponding higher order modes. It can be observed in the figure that the length, $\Delta L$, of the antenna in $x$-axis is approximately quarter wavelength of $740 \mathrm{MHz}$. Switches Sa1, Sa2, .., Sa8 and Sb1, Sb2, .., Sb8 located at specific positions are used to switch the operating frequencies, while Sc0Sd0, Sc1Sd1, ..., Sc8Sd8 and Se0Sf0 to Se1Sf1 are used to shorten the antenna. The switches Sc and $S d$ are connected in parallel to join each part of stub 1 while the Se and Sf switches for stub 2. When the antenna operates at $740 \mathrm{MHz}$, it has two higher order modes operating at $2020 \mathrm{MHz}$ and $3020 \mathrm{MHz}$. At the moment, all switches are ON (as shown in Figure 1) to allow the antenna radiate at this frequency and at the same time suppress the higher order mode. It should be noted that the stubs have mismatched the antenna at the higher order mode and the concept is extended to other operating frequencies from $400 \mathrm{MHz}$ to $3.5 \mathrm{GHz}$. The band, switches condition, and the stub length are tabulated in Table 3.
Besides that, the terminal length, stub width, and stubs location need to be optimized for better performance. These parameters can provide sufficiently small reflections and avoid the appearance of undesired higher order modes. The configuration is proposed since it exhibits omnidirectional radiation pattern with low level of cross-polarization, as well as it can suppress higher order modes, although with a simple structure. The fractal technology applied allows minimization of the antenna size. Open circuit stub has been used to trap the higher order mode that acts as stubfilters. This antenna is simulated using numerical simulations and crosschecked by using the finite element method- (FEM-) based simulations.

The measured results of the return loss of Figure 1 are presented in Figure 2. Good agreement is observed between the results obtained using commercial software and measurement. They operate at these particular bands which directly depend on the switches states. The corresponding resonant frequency is also given in the figure. 


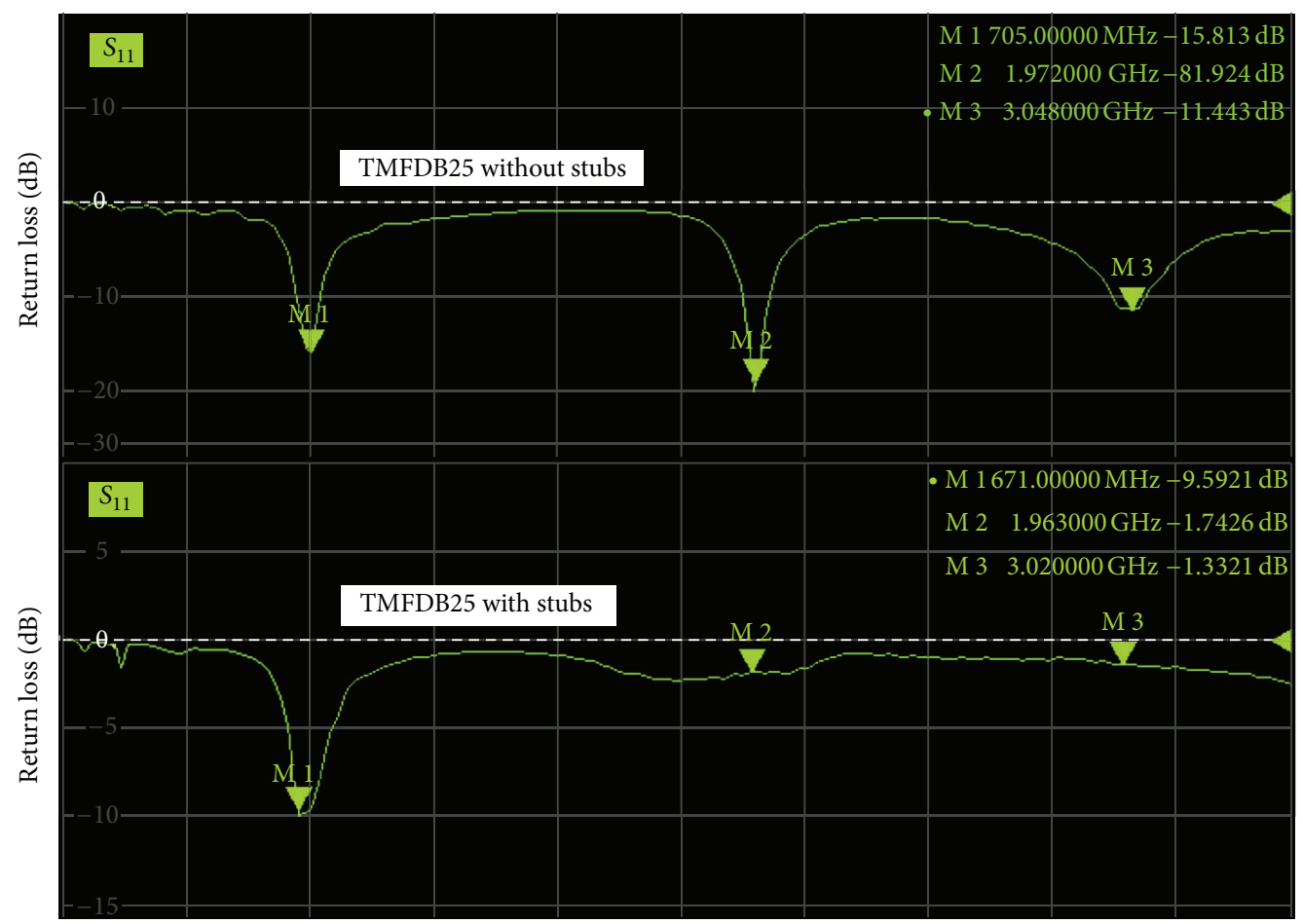

Frequency $(\mathrm{GHz})$

FIGURE 2: Measured return losses of the TMFDB25 antenna at two conditions: (1) TMFDB25 without stubs and (2) TMFDB25 with stubs 1, 2. In this study, $f$ equals $705 \mathrm{MHz}$ while $1 \mathrm{st} \mathrm{HM}=1.972 \mathrm{GHz}$ and 2 nd $\mathrm{HM}=3.048 \mathrm{GHz}$, and suppressed return losses of 1st $\mathrm{HM}$ and 2nd $\mathrm{HM}$ equals $-1.7429 \mathrm{~dB}$ and $-1.3321 \mathrm{~dB}$, respectively.

TABLE 6: Effect of stubfilter's width on resonance in Figure 1.

\begin{tabular}{|c|c|c|c|c|c|c|c|}
\hline Resonance & $\begin{array}{c}\Delta W_{3}, \mathrm{~mm} \\
1.0\end{array}$ & $\begin{array}{c}\Delta W_{4}, \mathrm{~mm} \\
1.5\end{array}$ & $\begin{array}{c}\Delta W_{5}, \mathrm{~mm} \\
2.0\end{array}$ & $\begin{array}{c}\Delta W_{6}, \mathrm{~mm} \\
2.5\end{array}$ & $\begin{array}{c}\Delta W_{7}, \mathrm{~mm} \\
3.0\end{array}$ & $\begin{array}{c}\Delta W_{8}, \mathrm{~mm} \\
3.5\end{array}$ & $\begin{array}{c}\Delta W_{9}, \mathrm{~mm} \\
4.0\end{array}$ \\
\hline$f(\mathrm{GHz}), \mathrm{dB}$ & $0.74,-25$ & $0.74,-29$ & $0.74,-36$ & $0.74,-25$ & $0.74,-23$ & $0.74,-19$ & $0.74,-17$ \\
\hline 1st $\mathrm{HM}(\mathrm{GHz}), \mathrm{dB}$ & $1.99,-4$ & $1.99,-4$ & $1.99,-4$ & $1.98,-3$ & $2.02,-1.6$ & $1.99,-3$ & $1.98,-3$ \\
\hline 2nd HM (GHz), dB & $2.35,-13$ & $2.33,-9$ & $2.3,-7$ & $2.27,-5$ & $2.79,-1.8$ & $2.27,-2$ & $2.27,-1.4$ \\
\hline
\end{tabular}

TABLE 7: Return losses and VSWR results of theoretical predictions versus measurement for TMFDB25 antenna.

\begin{tabular}{|c|c|c|c|c|c|c|c|c|c|}
\hline \multirow{3}{*}{$\begin{array}{l}\text { Band } \\
\text { Band } 1\end{array}$} & \multicolumn{6}{|c|}{ Return loss } & \multicolumn{3}{|c|}{ VSWR } \\
\hline & \multicolumn{2}{|c|}{ CST } & \multicolumn{2}{|c|}{ HFSS } & \multicolumn{2}{|c|}{ Measured } & \multirow{2}{*}{$\frac{\text { CST }}{1.468}$} & \multirow{2}{*}{$\begin{array}{c}\text { HFSS } \\
1.14900\end{array}$} & \multirow{2}{*}{$\begin{array}{c}\text { Measured } \\
1.5856\end{array}$} \\
\hline & $745 \mathrm{MHz}$ & $-14.4 \mathrm{~dB}$ & $733 \mathrm{MHz}$ & $-25.3784 \mathrm{~dB}$ & $691 \mathrm{MHz}$ & $-12.5 \mathrm{~dB}$ & & & \\
\hline Band 2 & $766 \mathrm{MHz}$ & $-16.4 \mathrm{~dB}$ & $754 \mathrm{MHz}$ & $-23.5454 \mathrm{~dB}$ & $720 \mathrm{MHz}$ & $-17.0 \mathrm{~dB}$ & 1.358 & 1.12704 & 1.4373 \\
\hline Band 3 & $801 \mathrm{MHz}$ & $-34.0 \mathrm{~dB}$ & $796 \mathrm{MHz}$ & $-23.5129 \mathrm{~dB}$ & $725 \mathrm{MHz}$ & $-24.5 \mathrm{~dB}$ & 1.041 & 1.14301 & 1.1157 \\
\hline Band 4 & $843 \mathrm{MHz}$ & $-36.8 \mathrm{~dB}$ & $838 \mathrm{MHz}$ & $-23.1433 \mathrm{~dB}$ & $734 \mathrm{MHz}$ & $-35.0 \mathrm{~dB}$ & 1.030 & 1.14969 & 1.0360 \\
\hline Band 5 & $903 \mathrm{MHz}$ & $-39.6 \mathrm{~dB}$ & $897.5 \mathrm{MHz}$ & $-23.6867 \mathrm{~dB}$ & $865 \mathrm{MHz}$ & $-17.0 \mathrm{~dB}$ & 1.022 & 1.13998 & 1.4367 \\
\hline Band 6 & $969 \mathrm{MHz}$ & $-39.5 \mathrm{~dB}$ & $960.5 \mathrm{MHz}$ & $-27.2084 \mathrm{~dB}$ & $953 \mathrm{MHz}$ & $-20.0 \mathrm{~dB}$ & 1.021 & 1.09119 & 1.3403 \\
\hline Band 7 & $1029 \mathrm{MHz}$ & $-31.4 \mathrm{~dB}$ & $1020 \mathrm{MHz}$ & $-29.0275 \mathrm{~dB}$ & $987 \mathrm{MHz}$ & $-15.0 \mathrm{~dB}$ & 1.055 & 1.07333 & 1.4221 \\
\hline Band 8 & $1099 \mathrm{MHz}$ & $-29.1 \mathrm{~dB}$ & $1104 \mathrm{MHz}$ & $-27.9649 \mathrm{~dB}$ & $1160 \mathrm{MHz}$ & $-27.0 \mathrm{~dB}$ & 1.099 & 1.08327 & 1.2220 \\
\hline Band 9 & $1190 \mathrm{MHz}$ & $-27.3 \mathrm{~dB}$ & $1195 \mathrm{MHz}$ & $-26.5608 \mathrm{~dB}$ & $1250 \mathrm{MHz}$ & $-19.5 \mathrm{~dB}$ & 1.090 & 1.09860 & 1.3705 \\
\hline Band 10 & $1270 \mathrm{MHz}$ & $-20.5 \mathrm{~dB}$ & $1282.5 \mathrm{MHz}$ & $-15.8776 \mathrm{~dB}$ & $1270 \mathrm{MHz}$ & $-16.5 \mathrm{~dB}$ & 1.210 & 1.38304 & 1.3993 \\
\hline Band 11 & $1428 \mathrm{MHz}$ & $-23.9 \mathrm{~dB}$ & $1429.5 \mathrm{MHz}$ & $-17.1505 \mathrm{~dB}$ & $1440 \mathrm{MHz}$ & $-16.5 \mathrm{~dB}$ & 1.136 & 1.32241 & 1.3863 \\
\hline Band 12 & $1596 \mathrm{MHz}$ & $-47.0 \mathrm{~dB}$ & $1597.5 \mathrm{MHz}$ & $-22.3475 \mathrm{~dB}$ & $1650 \mathrm{MHz}$ & $-18.0 \mathrm{~dB}$ & 1.009 & 1.16524 & 1.2535 \\
\hline Band 13 & $1879 \mathrm{MHz}$ & $-30.3 \mathrm{~dB}$ & $1916 \mathrm{MHz}$ & $-45.262 \mathrm{~dB}$ & $1880 \mathrm{MHz}$ & $-19.5 \mathrm{~dB}$ & 1.063 & 1.01097 & 1.2723 \\
\hline Band 14 & $2345 \mathrm{MHz}$ & $-32.4 \mathrm{~dB}$ & $2458.5 \mathrm{MHz}$ & $-18.946 \mathrm{~dB}$ & $2350 \mathrm{MHz}$ & $-18.0 \mathrm{~dB}$ & 1.049 & 1.25454 & 1.2737 \\
\hline Band 15 & $2922 \mathrm{MHz}$ & $-34.5 \mathrm{~dB}$ & $3074 \mathrm{MHz}$ & $-18.4166 \mathrm{~dB}$ & $3010 \mathrm{MHz}$ & $-40.0 \mathrm{~dB}$ & 1.039 & 1.27271 & 1.0207 \\
\hline
\end{tabular}



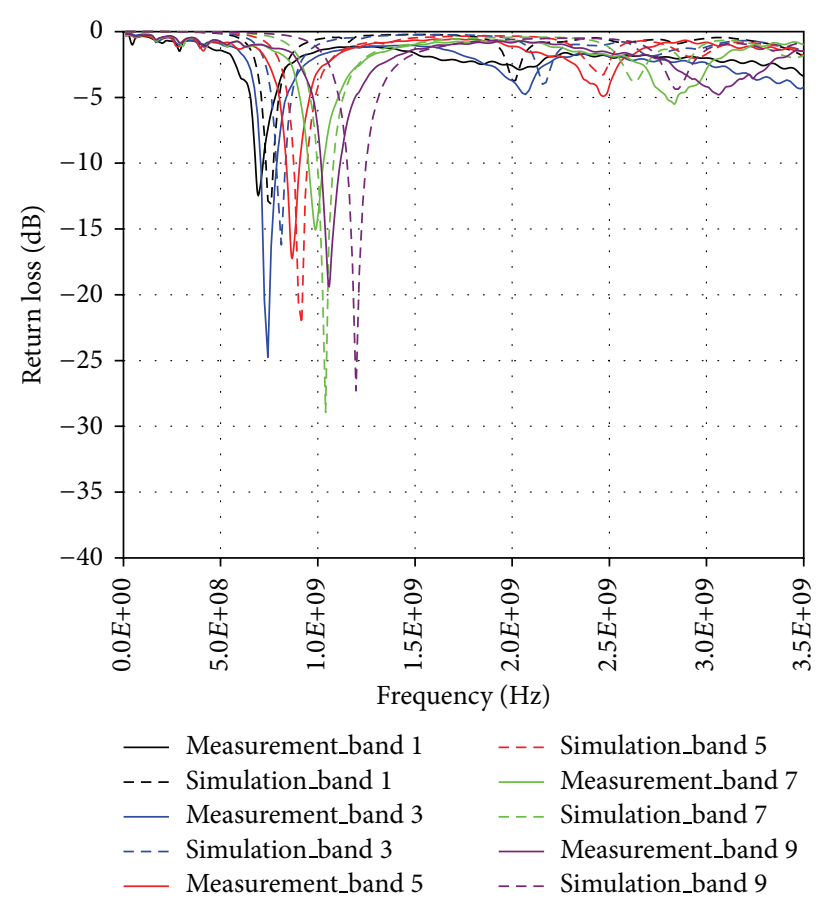

Figure 3: Simulated and measured return losses at Bands 1, 3, 5, 7, and 9.

\section{Results and Discussion}

3.1. Antenna Optimization-Parametric Study. In this section, three important antenna parameters in Figure 1 which are the terminal length, $L$, distance between stubs, $\Delta L_{1-2}$, and the stub's widths, $\Delta W$, are studied. By means of varying these parameters in uniform increment, the following data are obtained. The effect of the operating frequency, 1st HM and 2nd HM are observed as shown in the table.

Table 4 tabulates the simulated resonance frequency for antenna when the antenna terminal length is changed from $10 \mathrm{~mm}$ to $22 \mathrm{~mm}$. Results show that the antenna resonates at $740 \mathrm{MHz}$ in the range from 0 to $3.5 \mathrm{GHz}$ with different return losses. When the terminal length is increased, a better return loss is achieved, whereby this action brings the line impedance value to the point closer to the characteristic impedance. The $10 \mathrm{~mm}$ length is selected due to its smaller size.

Cautious steps are taken to ensure the investigation is valid. The effect of stub location is highlighted in Table 5. Actual length of the antenna terminal is approximately $8 \mathrm{~mm}$. The variation starts from $0 \mathrm{~mm}$ to $6 \mathrm{~mm}$ with an increment of $1 \mathrm{~mm}$ each. It is shown that the antenna can maintain the resonant frequency at $740 \mathrm{MHz}$ with excellent return loss of $<-20 \mathrm{~dB}$ although the stub location is varied. The stub location of $3 \mathrm{~mm}$ totally rejected the higher order mode. However, there is harmonic frequency for certain conditions.

Table 6 tabulates the resonance frequency for antenna when the stub width is changed from $1 \mathrm{~mm}$ to $4 \mathrm{~mm}$. The antenna has first resonance at $740 \mathrm{MHz}$ with different return losses for all cases. The width of $3 \mathrm{~mm}$ totally rejected the harmonic frequencies and has good return loss of $-23 \mathrm{~dB}$
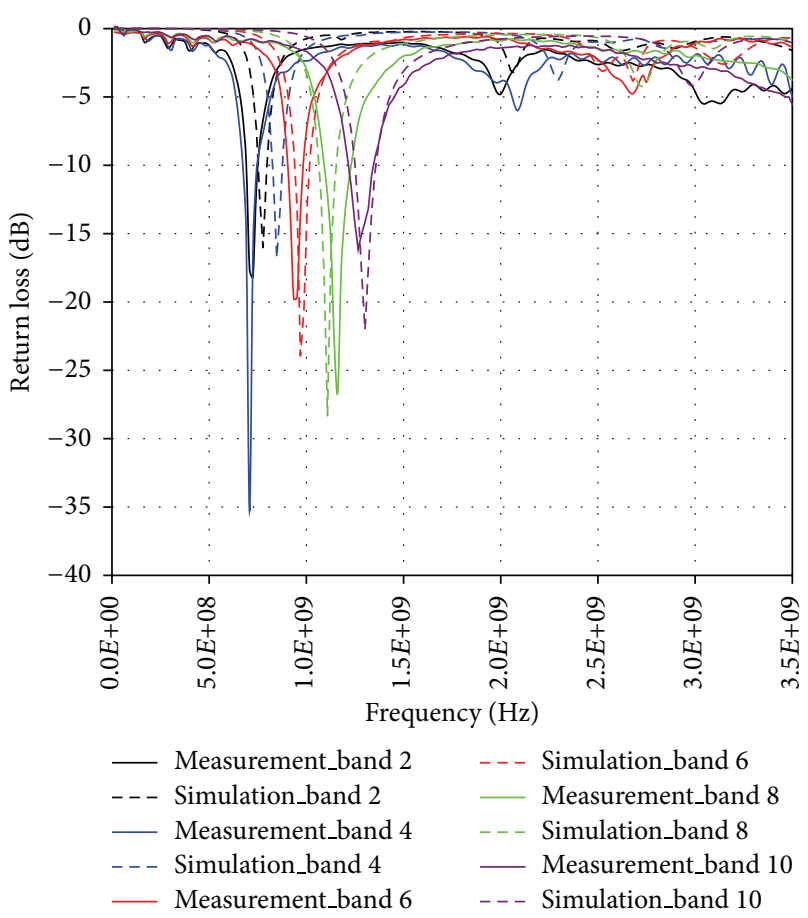

FIgURE 4: Simulated and measured return losses at Bands 2, 4, 6, 8, and 10.

for the operating frequency. These optimum parameters have been used in the designing of the TMFDB25 antenna.

3.2. TMFDB25 Antenna. Basically, the proposed antenna is constructed by measuring its electrical properties in order to verify the theoretical and simulation results. The selection of this antenna to be developed is based on small size upon optimization and excellent performance. To achieve fifteenband TMFDB25 antenna, a small strip of copper is used as the substitute for the RF switches. Then, to be a fifteen-band TMFDB25 antenna with suppressed higher order modes, the stubs are connected. They enlarged the number of small strips of copper. The latter is soldered to the radiating element as well as the stub sections at the switch locations to simulate the switch $\mathrm{ON}$ states. The copper strips are made from the standard copper tape and are approximately $0.2 \mathrm{~mm}$ wide. The tape switches are sufficiently long enough $(2 \mathrm{~mm})$ to both span the $1 \mathrm{~mm}$ gap separating the radiating element and the stub length. It provides enough metal-to-metal contact for good solder joint. In addition, for good presentation, the switch has been labeled as black colour for ON states and a cross-line (red colour) for OFF states.

The corresponding measured results of the return loss are depicted in Figures 3 to 5. It should be noted that this research work is very challenging and requires huge amount of measurement period. However, they are successful to be plotted. The huge numbers of switches have been used and hence increase the difficulty to suppress the higher order modes.

Then the measured results are compared with the simulation works. It can be seen in Figure 3 that the designed 

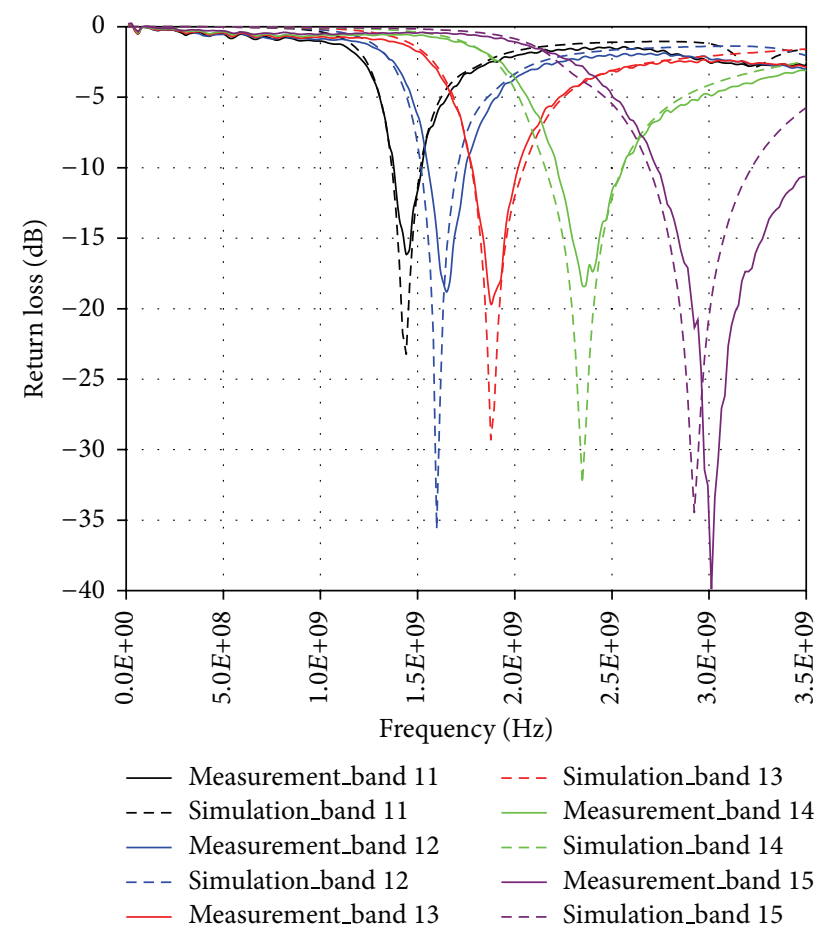

FIGURE 5: Simulated and measured return losses at bands 10, 11, 12, 13,14 , and 15 .

antenna can be tuned from band $1=691 \mathrm{MHz}$, band $3=$ $725 \mathrm{MHz}$, band $5=865 \mathrm{MHz}$, band $7=987 \mathrm{MHz}$, and band 9 $=1270 \mathrm{MHz}$ while the simulated are band $1=745 \mathrm{MHz}$, band $3=801 \mathrm{MHz}$, band $5=903 \mathrm{MHz}$, band $7=1029 \mathrm{MHz}$, and band $9=1190 \mathrm{MHz}$ at a time.

It can also be observed in Figure 4 that the antenna can be tuned from bands 2, 4, 6, 8, and 10 with suppressed higher modes. In this case, the measurements are band $2=725 \mathrm{MHz}$, band $4=734 \mathrm{MHz}$, band $6=953 \mathrm{MHz}$, band $8=1160 \mathrm{MHz}$, and band $10=1270 \mathrm{MHz}$ while the simulated are band $2=$ $766 \mathrm{MHz}$, band $4=843 \mathrm{MHz}$, band $6=969 \mathrm{MHz}$, band $8=$ $1099 \mathrm{MHz}$, and band $10=1270 \mathrm{MHz}$.

Then, in Figure 5, the antenna tuned the bands from bands 11, 12, 13,14, and 15 with suppressed higher modes. (Measured: band $11=1440 \mathrm{MHz}$, band $12=1650 \mathrm{MHz}$, band $13=1880 \mathrm{MHz}$, band $14=2350 \mathrm{MHz}$, and band $15=$ $3010 \mathrm{MHz}$ while the simulated are band $11=1428 \mathrm{MHz}$, band $12=1596 \mathrm{MHz}$, band $13=1879 \mathrm{MHz}$, band $14=2345 \mathrm{MHz}$, and band $15=2922 \mathrm{MHz}$ ). The bandwidth covering tunable ranges are obtained as $1659 \mathrm{MHz}$. The corresponding measured return losses are $-12.5 \mathrm{~dB}$ (band 1 ), $-17 \mathrm{~dB}$ (band 2), $-24.5 \mathrm{~dB}$ (band 3), $-35 \mathrm{~dB}$ (band 4), $-17 \mathrm{~dB}$ (band 5), $-20 \mathrm{~dB}$ (band 6), $-31.4 \mathrm{~dB}$ (band 7), $-27 \mathrm{~dB}$ (band 8), $-27.3 \mathrm{~dB}$ (band 9), $-16.5 \mathrm{~dB}$ (band 10), $-16.5 \mathrm{~dB}$ (band 11), $-18 \mathrm{~dB}$ (band 12), $-19.5 \mathrm{~dB}$ (band 13), $-18.0 \mathrm{~dB}$ (band 14), and $-34.5 \mathrm{~dB}$ (band 15).

The simulation of the operating frequencies (bands 1,2 , and 3 to 15) of the TMFDB25 antenna with stubs has been done using CST code and HFSS code (not shown in this paper due to limited number of pages).

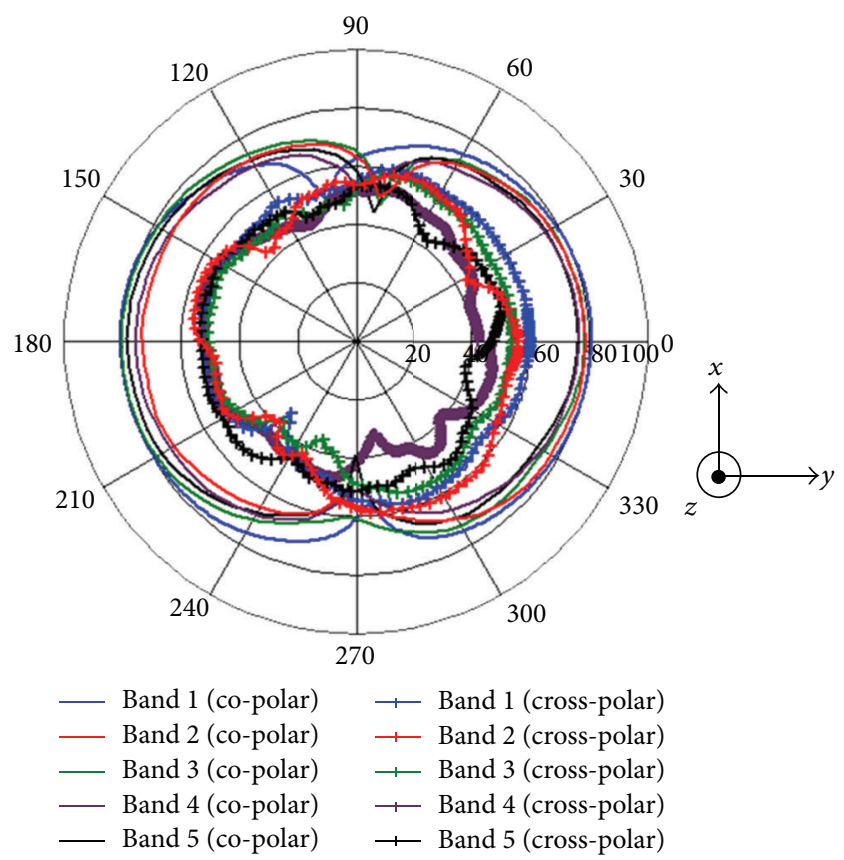

FIGURE 6: Measured E-plane radiation patterns (co-polar \& crosspolar) at operating frequency, $f$, for TMFDB25 with stubs 1, 2 at bands 1 to 5 .

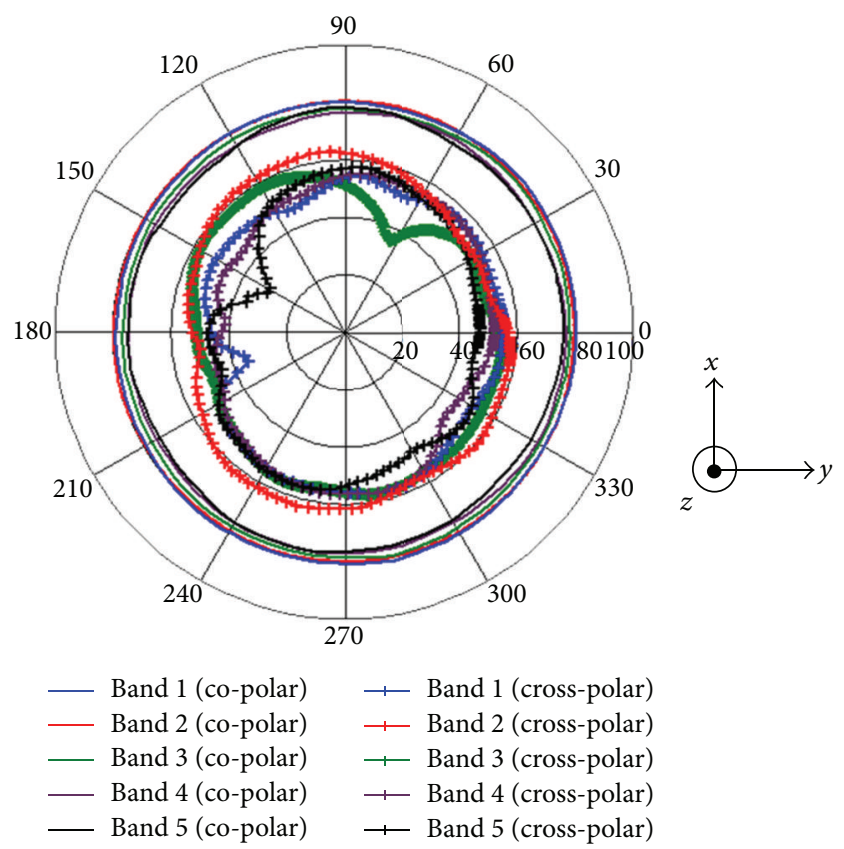

FIgURE 7: Measured H-plane radiation patterns (co-polar \& crosspolar) at operating frequency, $f$, for TMFDB25 with stubs 1, 2 at bands 1 to 5 .

Table 7 presents the simulated (CST code and HFSS code) and measured return losses and corresponding VSWR performances of the TMFDB25 antenna for each band. The antenna can be tuned to a single frequency at a time as tabulated in the table. The stubs have effectively reduced the input 


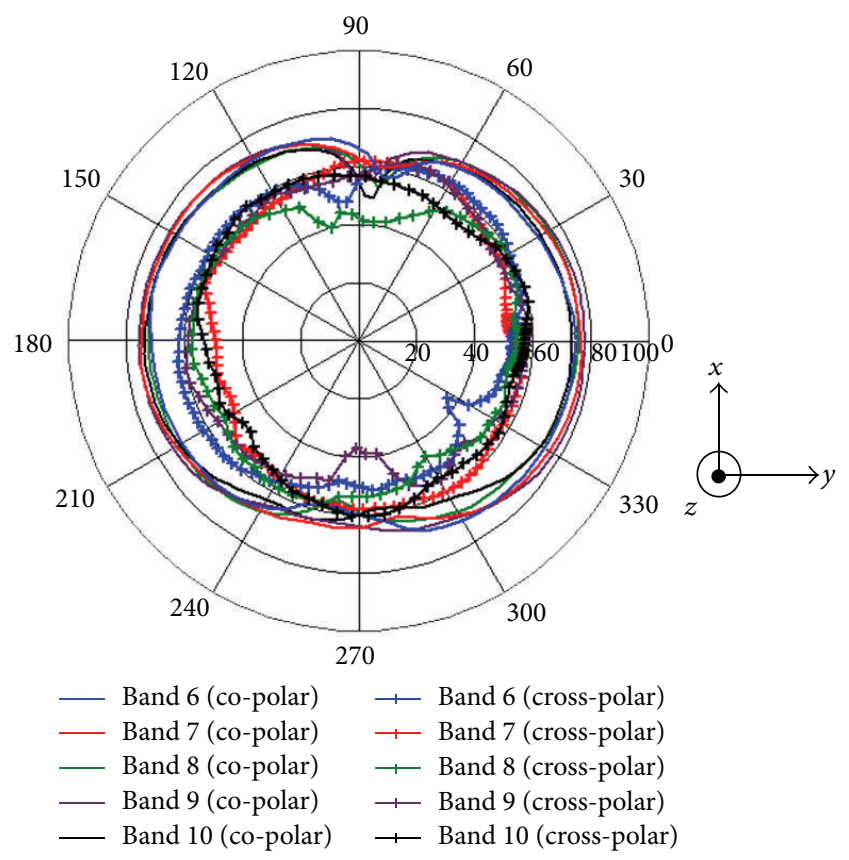

Figure 8: Measured E-plane radiation patterns (co-polar \& crosspolar) at operating frequency, $f$, for TMFDB2 5 with stubs 1,2 at bands 6 to 10 .

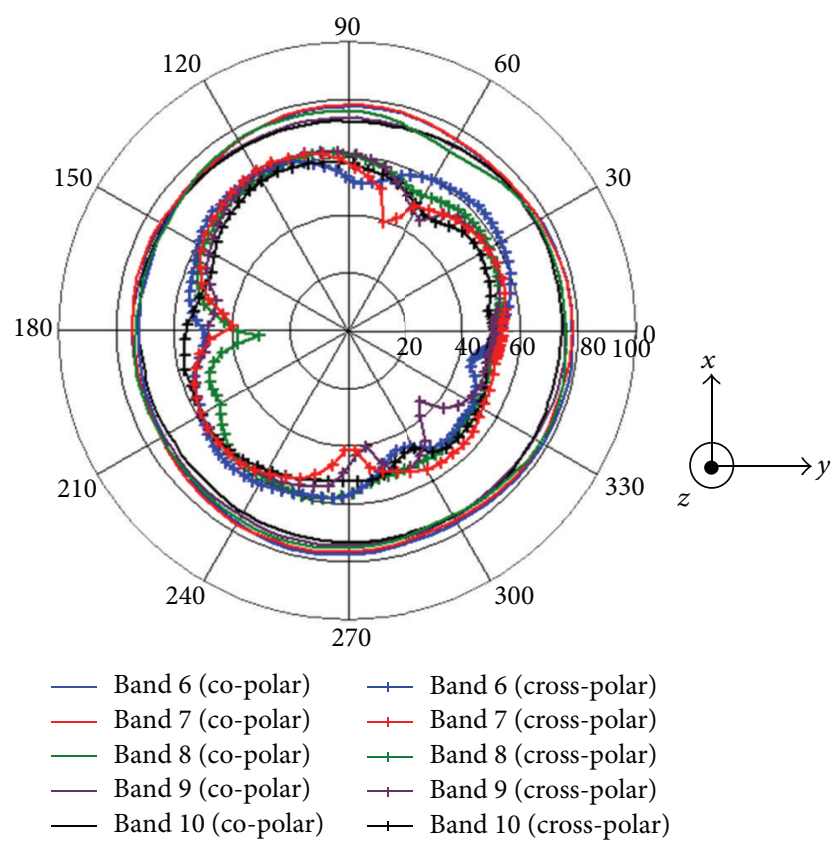

Figure 9: Measured H-plane radiation patterns (co-polar \& crosspolar) at operating frequency, $f$, for TMFDB25 with stubs 1, 2 at bands 6 to 10 .

reflections and thus corresponding VSWRs. Channel operating bandwidths is obtained by CST, HFSS, and measurements are $2177 \mathrm{MHz}, 2341 \mathrm{MHz}$, and $2319 \mathrm{MHz}$, respectively. Good agreement is observed for the measurement and simulation results in terms of operating frequencies, return losses, and VSWRs. The main factor that contributes to the measurement

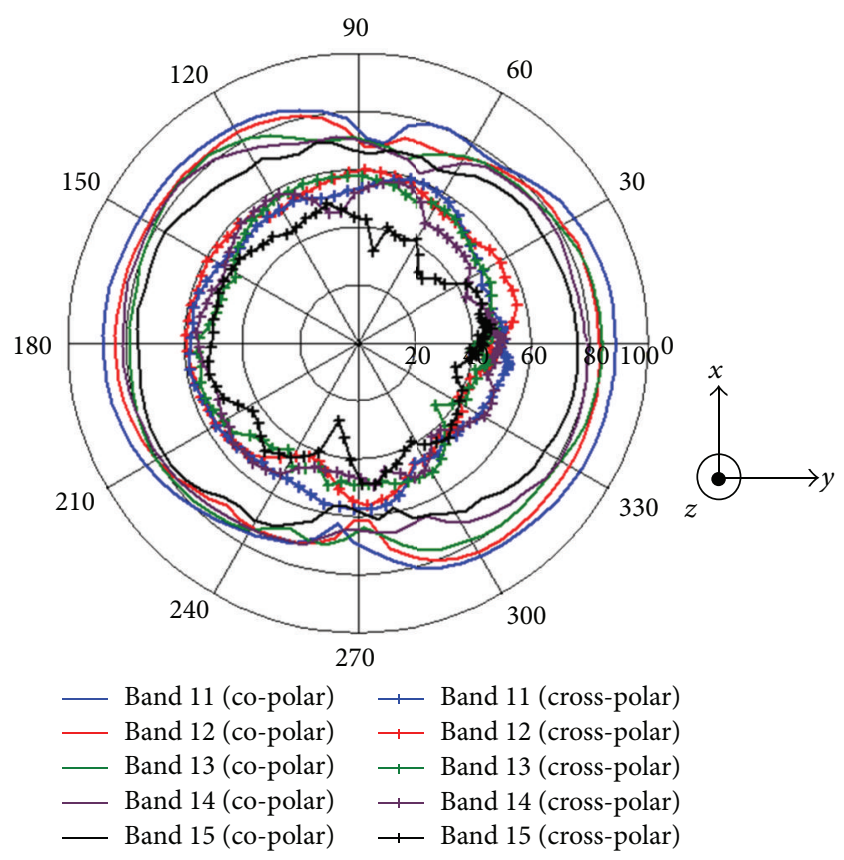

Figure 10: Measured E-Plane radiation patterns (co-polar \& crosspolar) at operating frequency, $f$, for TMFDB25 with stubs 1,2 at bands 11 to 15 .

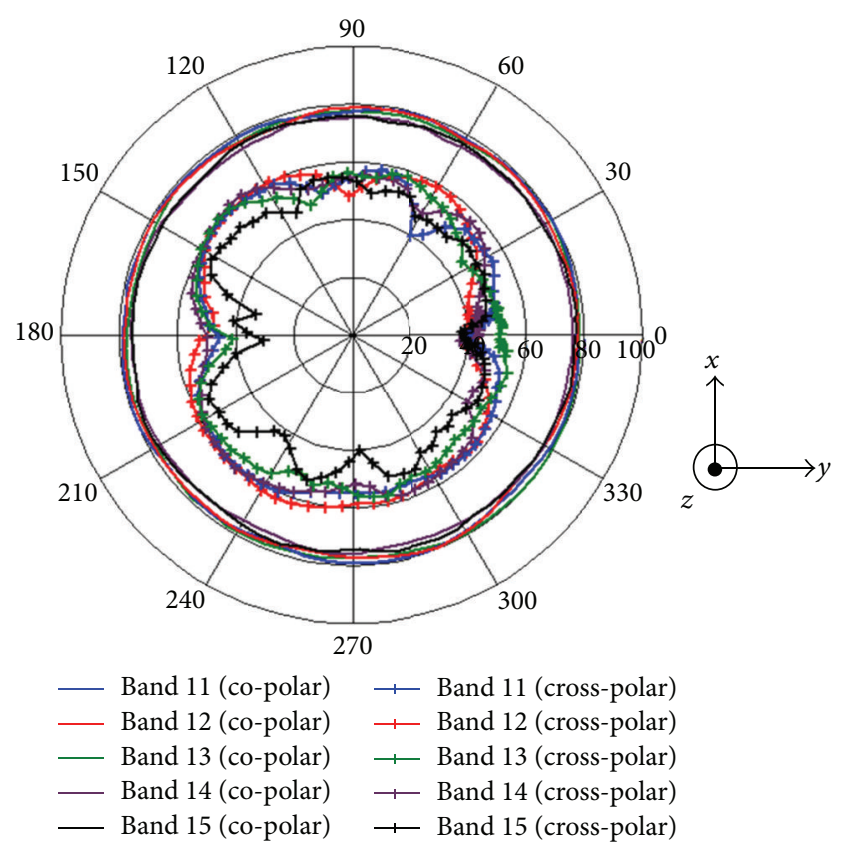

Figure 11: Measured H-plane radiation patterns (co-polar \& crosspolar) at operating frequency, $f$, for TMFDB25 with stubs 1,2 at bands 10 to 15 .

results is a little bit different compared to the simulation data due to the imperfect work during soldering of the copper to join each stub segment.

In this study, the corresponding measured E-plane and $\mathrm{H}$-plane radiation patterns at the operating frequencies in Figures 3 to 5 are presented in Figures 6, 7, 8, 9, 10, and 
11, respectively. These figures provide the $\mathrm{H}$-plane ( $x-z$ axis) and the E-plane ( $z-x$ axis) patterns for bands 1 to 15 . In this work, it is found that the pattern behavior for the fifteen bands antenna resembles that of a simple dipole antenna. The patterns are closed to omnidirectional in the $\mathrm{H}$-plane, having a figure-of-eight pattern in the E-plane.

As predicted by the simulations, the radiation patterns of most bands remain nearly constant from one switch state to the next. This situation is desired for the antenna in order to maintain the performance while selecting the operating frequency. This consistency can be clearly seen in the pattern comparison of bands 1 to 15 .

\section{Conclusion}

TMFDB25 antenna with harmonic suppression capability that is suitable for frequency reconfiguration in the frequency bands of TV ( $400 \mathrm{MHz}-800 \mathrm{MHz}$ ), GSM900/1800 MHz, 3G, ISM $2.4 \mathrm{GHz}$, and above (up to $3.5 \mathrm{GHz}$ ) is presented. The TMFDB25 is an improvement on the conventional linear dipole antenna with harmonic suppressed behavior. A total of $50 \mathrm{RF}$ switch locations were incorporated into the design to achieve the desired frequency reconfigurable performance. Single operating frequency out of fifteen bands can be selected by changing the antenna's length, and the stub is used to suppress the harmonic frequency. The proposed TMFDB25 antenna has a practical size with $51.8 \%$ size reduction compared to the reference [1]. The corresponding measured return loss and VSWR are found to be in good agreement with the computed performances. The simulated and measured data demonstrate that the antenna indeed provides the desired wideband frequency reconfiguration. The number of operating frequency can be increased by increasing the number of switches. In addition, an omniradiation pattern is maintained for the whole frequency. The performance verifies the proposed design concept. From the simulation and experimental results, it can be concluded that the proposed antennas have a unique structure compared to the available published "harmonic suppressed reconfigurable antenna" or "reconfigurable fractal antenna."

\section{Acknowledgments}

The work is supported by Universiti Teknologi Malaysia, Research University Grant vote 04J25 and PY/2012/01578, and Ministry of Education Malaysia, Fundamental Research Grant Scheme vote 4F039. The authors are grateful to Universiti Tun Hussein Onn Malaysia for supporting PhD studies of S. A. Hamzah. Simulations were done at the Radio Communication and Antenna Design Laboratory (RACAD), UTHM. Measurements were performed at EMC centre, UTHM.

\section{References}

[1] A. Mirkamali, P. S. Hall, and M. Soleimani, "Reconfigurable printed-dipole antenna with harmonic trap for wideband applications," Microwave and Optical Technology Letters, vol. 48, no. 5, pp. 927-929, 2006.
[2] A. Mirkamali, P. S. Hall, and M. Soleiman, "Wideband frequency reconfiguration of a printed log periodic dipole array," Microwave and Optical Technology Letters, vol. 52, no. 4, pp. 861864, 2010.

[3] N. P. Chamming, Active antenna bandwidth control using reconfigurable antenna elements [Ph.D. thesis], Virginia Polytechnic Institute \& State University, 2003.

[4] X.-S. Yang, B.-Z. Wang, and Y. Zhang, "A reconfigurable Hilbert curve patch antenna," in Proceedings of the IEEE Antennas and Propagation Society International Symposium and USNC/URSI Meeting, pp. 613-616, July 2005.

[5] W. Wu, B.-Z. Wang, X.-S. Yang, and Y. Zhang, "A patternreconfigurable planar fractal antenna and its characteristicmode analysis," IEEE Antennas and Propagation Magazine, vol. 49, no. 3, pp. 68-75, 2007.

[6] Y. Zhang, B.-Z. Wang, and X.-S. Yang, "Fractal Hilbert microstrip antennas with reconfigurable radiation patterns," Microwave and Optical Technology Letters, vol. 49, no. 2, pp. 352-354, 2007.

[7] D. E. Anagnostou, G. Zheng, M. T. Chryssomallis et al., "Design, fabrication, and measurements of an RF-MEMS-based selfsimilar reconfigurable antenna," IEEE Transactions on Antennas and Propagation, vol. 54, no. 2, pp. 422-432, 2006.

[8] K. J. Vinoy and V. K. Varadan, "Design of reconfigurable fractal antennas and RF MEMS for space based system," Optical Engineering, vol. 4591, pp. 185-196, 2001.

[9] H. Lui, B. Z. Wang, and W. Shao, "Dual band bi-directional pattern reconfigurable fractal patch antenna for milimeter wave application," International Journal of Infrared and Millimeter Waves, vol. 28, no. 1, pp. 25-31, 2007.

[10] J. S. Petko and D. H. Werner, "Miniature reconfigurable threedimensional fractal tree antennas," IEEE Transactions on Antennas and Propagation, vol. 52, no. 8, pp. 1945-1956, 2004.

[11] N. Kingsley, D. E. Anagnostou, M. M. Tentzeris, and J. Papapolymerou, "RF MEMS sequentially reconfigurable sierpinski antenna on a flexible organic substrate with novel DC-biasing technique," Journal of Microelectromechanical Systems, vol. 16, no. 5, pp. 1185-1192, 2007.

[12] W. Kang, K. H. Ko, and K. Kim, "A compact beam reconfigurable antenna for symmetric beam switching," Progress In Electromagnetics Research, vol. 129, pp. 1-16, 2012.

[13] C. C. Wang, L. T. Chen, and J. S. Row, "Reconfigurable Slot antenna with circular polarization," Progress In Electromagnetics Research, vol. 34, pp. 101-110, 2012.

[14] A. H. Ramadan, K. Y. Kabalan, A. El-Hajj, S. Khoury, and M. Al-Husseini, "A reconfigurable U-Koch microstrip antenna for wireless applications," Progress in Electromagnetics Research, vol. 93, pp. 355-367, 2009.

[15] N. Romano, G. Prisco, and F. Soldovieri, "Design of a reconfigurable antenna for ground penetrating radar applications," Progress in Electromagnetics Research, vol. 94, pp. 1-18, 2009.

[16] S. Manafi, S. Nikmehr, and M. Bemani, "A planar reconfigurable multifunctional antenna for WLAN/WiMAX/UWB/PCS-DCS/ UMTS applications," Progress In Electromagnetics Research C, vol. 26, pp. 123-137, 2012.

[17] M. Al-Husseini, M. A. Madi, A. H. Ramadan, K. Y. Kabalan, and A. El-Hajj, "A reconfigurable cedar-shaped microstrip antenna for wireless applications," Progress In Electromagnetics Research C, vol. 25, pp. 209-221, 2011.

[18] S. A. Hamzah and M. Esa, "Miniaturized single band microwave fractal dipole antenna and its tunable configuration," in Proceedings of the of IEEE APS, pp. 1-4, July 2010. 

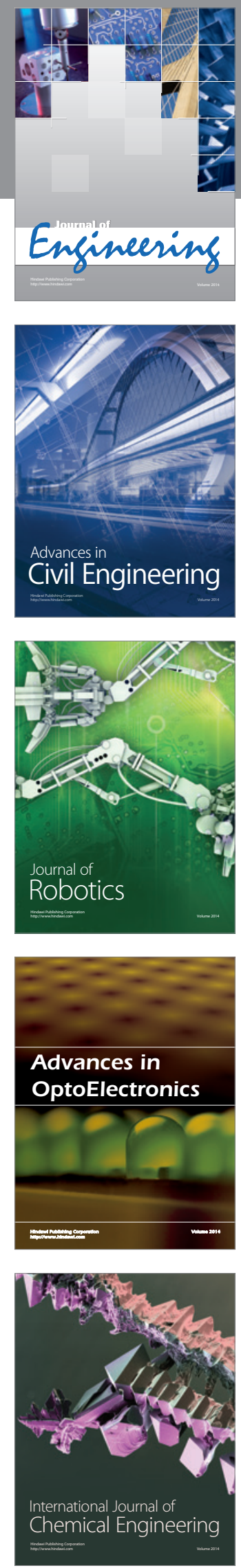

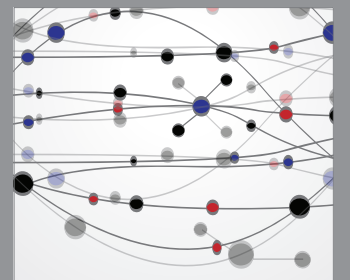

The Scientific World Journal
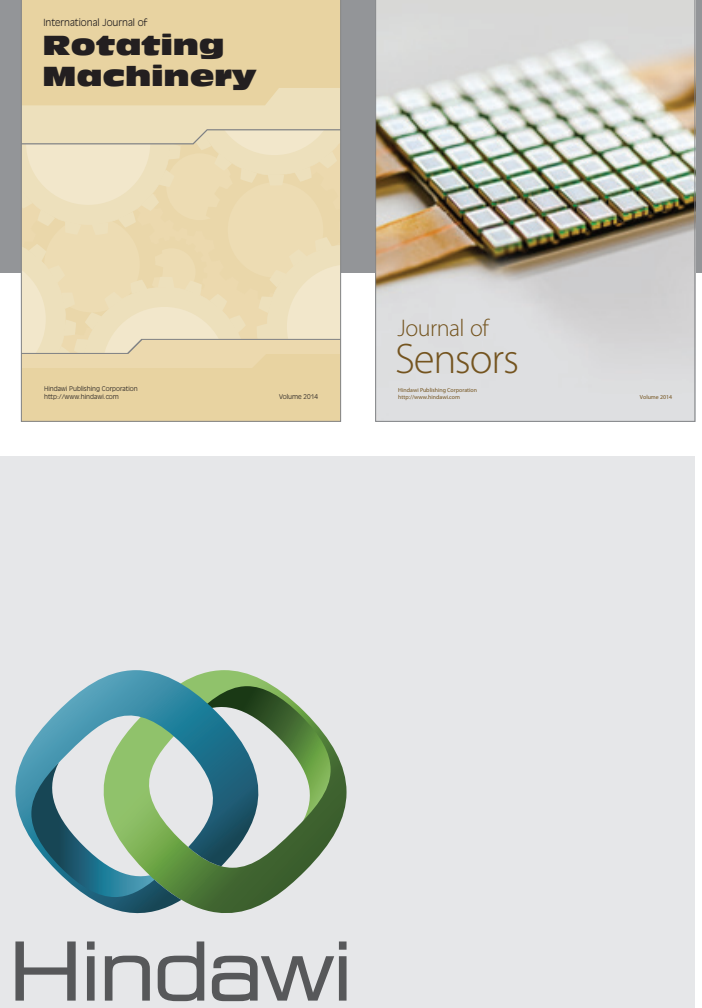

Submit your manuscripts at http://www.hindawi.com
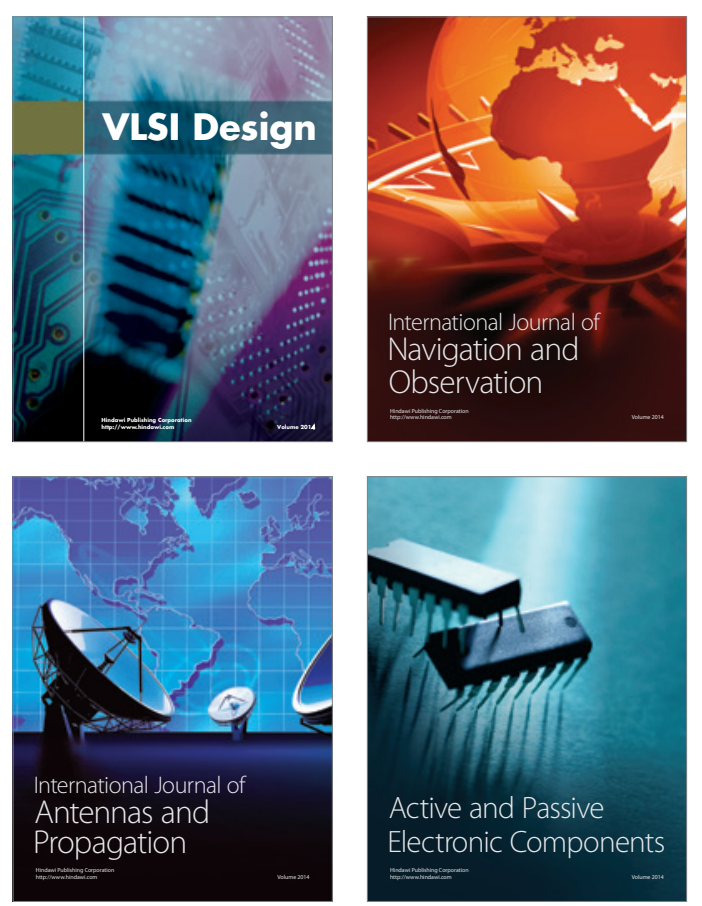
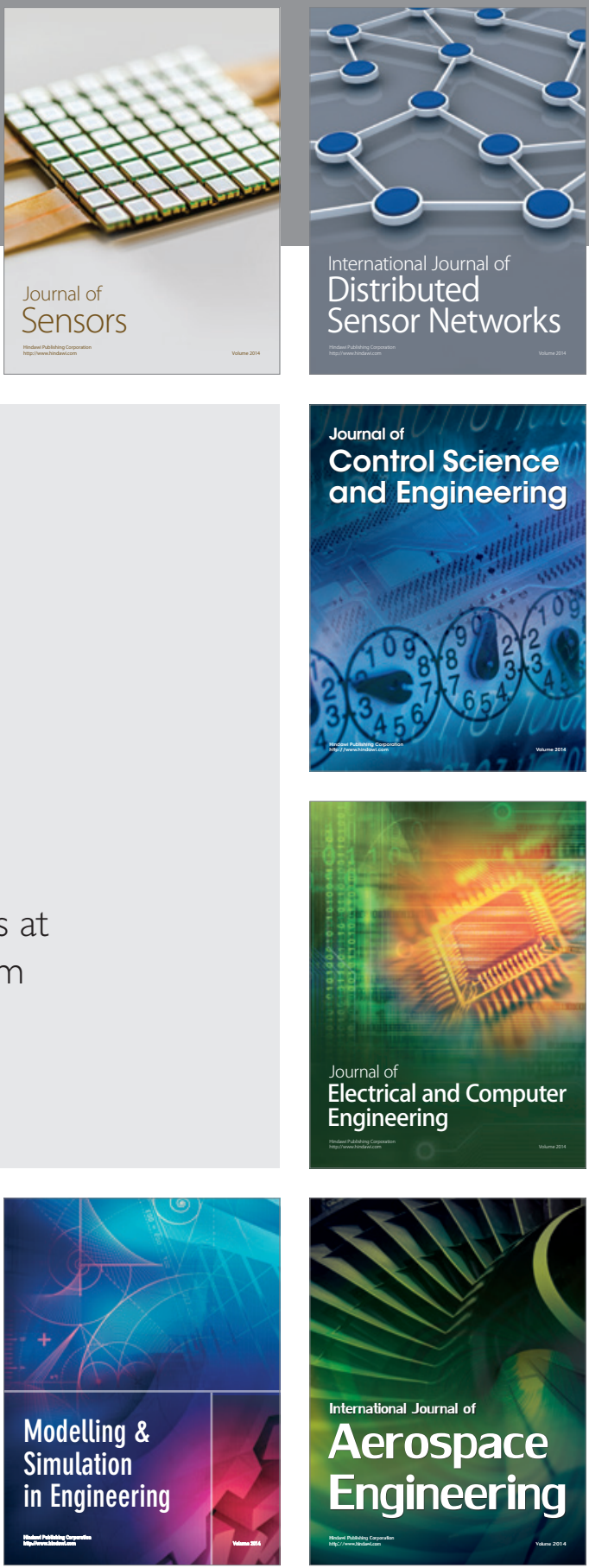

Journal of

Control Science

and Engineering
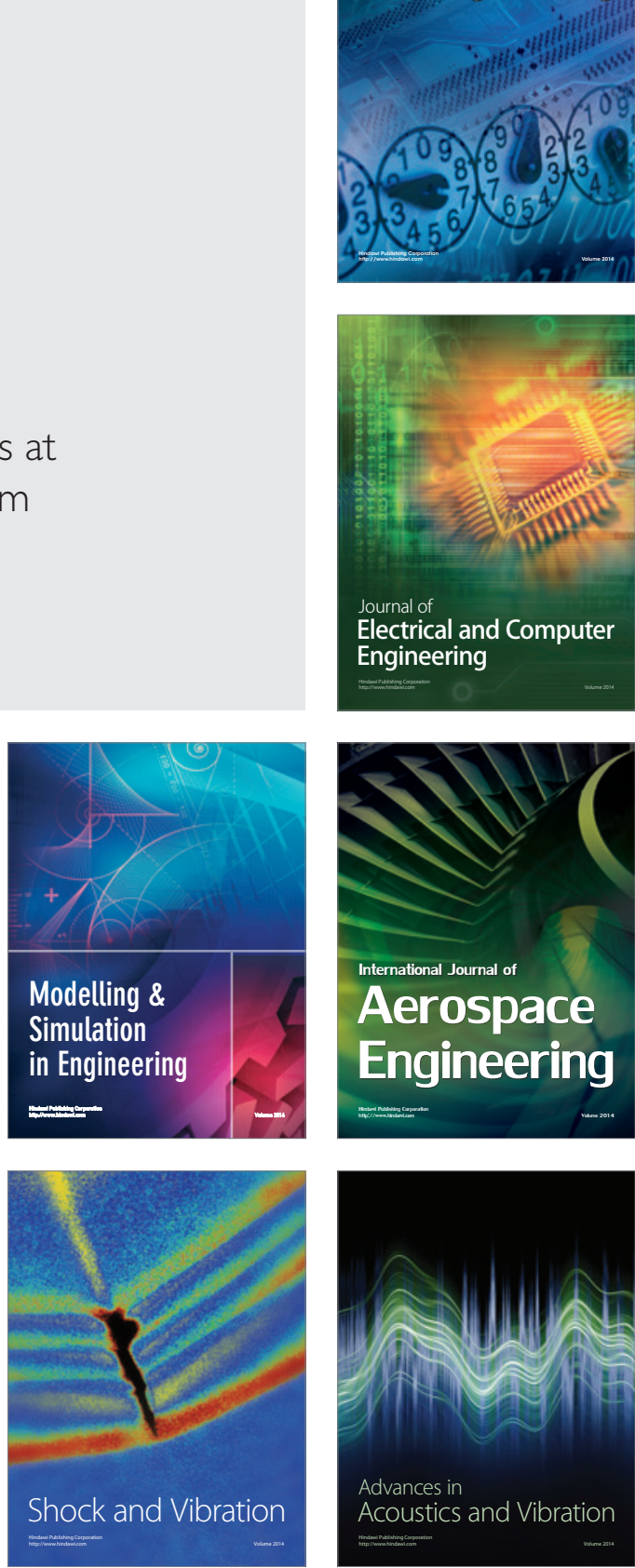